\title{
Physico-chemical Characteristics of Pulverized Coals and Their Interrelations- A Spontaneous Combustion and Explosion Perspective
}

Devi Prasad Mishra ( $\boldsymbol{D}$ dpmishra@iitism.ac.in )

IIT (ISM): Indian Institute of Technology

\section{Research Article}

Keywords: Pulverized coal, bulk density, particle size, specific surface area, spontaneous combustion, explosion

Posted Date: September 27th, 2021

DOI: https://doi.org/10.21203/rs.3.rs-828214/v1

License: (1) (1) This work is licensed under a Creative Commons Attribution 4.0 International License. Read Full License

Version of Record: A version of this preprint was published at Environmental Science and Pollution Research on November 26th, 2021. See the published version at https://doi.org/10.1007/s11356-02117626-9. 
8 Characteristics of pulverized coals have significant influence on the spontaneous combustion and explosion

9 processes. This paper presents an experimental and theoretical framework on physico-chemical characteristics of 10 coal and analyzes their interrelations from spontaneous combustion and explosion perspectives. The chemical 11 properties, morphology, bulk density, particle size and specific surface area of pulverized coals from nine different

12 coal subsidiaries of India are vividly investigated in five distinct sizes. Moreover, the effects of particle size on bulk

13 density, specific surface area and $\mathrm{N}_{2}$ adsorption capacity of pulverized coals are critically analyzed. The

14 micrographs revealed that the coal particles are mostly irregular in shape with angular outlines and sharp edges.

15 With decrease in particle size, the bulk density of pulverized coals decreased and the specific surface area and $\mathrm{N}_{2}$

16 adsorption capacity increased. The relationships of bulk density and specific surface area of pulverized coals with

17 particle size are established. Moreover, the specific surface areas determined by both the particle sizing and BET

18 methods are compared and correlation factors between them are determined. This study led to the generation of 19 insightful coal characteristic data which can be used as reference material for furthering researches on spontaneous 20 combustion and explosion involving pulverized coals.

22 Keywords: Pulverized coal; bulk density; particle size; specific surface area; spontaneous combustion; explosion. 


\section{1. Introduction}

25 Coal still maintains its legacy as the largest source of energy across the globe. Pulverized coal finds applications as

26 raw material in several process industries, wherein its physical properties, viz. bulk density, shape, size, surface

27 texture, moisture content, etc. play a major role. Bulk density is a useful parameter in the characterization and

28 handling of coal. Under a given processing condition, the bulk density of coal is significantly affected by the particle

29 size distribution and moisture content among many other factors (Yu et al., 1995; Braga et al., 2019). In contrast,

30 coal dust explosion and spontaneous combustion of coal leading to fire are the two major threats to the safety of coal

31 mines, process industries and utilities sector (Amyotte et al., 2003; Yuan et al., 2015; Yong et al., 2019). Apart from

32 imposing direct threat, they pollute the workplace and surrounding environment and adversely affect the human

33 health by releasing harmful toxic gases, combustion residues and significant amounts of particulates (Li et al.,

34 2020). Coal dust produced during the mining process constitutes one of the major causes of explosion (Cashdollar,

35 1996; Mishra and Azam, 2018) and health hazards in coal mines (Laney and Weissman, 2014). Yuan et al. (2015)

36 reported that coal dust contributes to $35 \%$ of the dust explosions in China and one of the main causes of the

37 explosions is high dependence on coal for energy consumption.

38 The particle size and surface area of pulverized coal are often correlated and greatly influence the 39 spontaneous combustion susceptibility and explosion severity of coal dust (Cashdollar, 1996; Mishra and Azam,

40 2018; Azam and Mishra, 2019; Li et al., 2020; Pan et al., 2020). The explosibility and spontaneous combustion

41 susceptibility or oxidation rate of coal increase with increase in the fineness and exposed surface area of coal. The

42 finer the pulverized coal particle size, the greater the exposed specific surface area available for oxygen adsorption,

43 the stronger the coal oxidation and coal-oxygen recombination abilities, and the greater the susceptibility of coal to

44 spontaneous combustion (Pan et al., 2020). Hence, characterization of particle size and surface area of pulverized

45 coal is important from the spontaneous combustion susceptibility and explosion severity assessment perspectives.

46 In recent years, the effects of particle size and surface area on ignition sensitivity (Amyotte et al., 1993;

47 Mishra and Azam, 2018; Azam and Mishra, 2019), explosibility (Cashdollar, 2000; Gao et al., 2010; Harris et al.,

48 2015; Li et al., 2016; Cao et al., 2012; Liu et al., 2018) and spontaneous combustion susceptibility (Rifella et al.,

49 2019; Li et al., 2020) of pulverized coals are being extensively investigated by the researchers worldwide. These

50 studies used pulverized coals in various size ranges for experimentation. Mishra and Azam Mishra and Azam (2018) 
51 studied the effects of particle size on minimum ignition temperature (MIT) and combustion process of coal dust in 52 five different sizes ranges. Hosseinzadeh et al. (2019) studied the minimum ignition energy (MIE) to assess the 53 explosion risk of six different dusts, including Indonesian coal dust cloud, based on their particle size distribution, 54 density and flammability. Li et al. (2016) studied the effects of particle size $\left(\mathrm{D}_{50}\right)$ and size dispersity $\left(\sigma_{\mathrm{D}}\right)$ on 55 explosion severity of coal dust and observed that the presence of finer particles greatly increases the total effective 56 specific surface area and speed up the devolatilization rate, which would accelerate the dust explosion process. Li et

57 al. (2020) investigated the influence of fuel concentration and coal particle size on multiple explosion parameters for 58 methane-coal particle mixtures. They considered coal dust particles in three sizes, such as 38,48 and $75 \mu \mathrm{m}$ for the 59 experiments. Li et al. (2020) studied the effects of particle size on self-ignition behaviour of coal dust layer on a hot 60 plate in three different size ranges, viz. 100-150, 150-200 and 200-300 $\mu \mathrm{m}$. Xu et al. (2020) investigated the 61 microstructure and oxidation reactivity of crushed coal of different ranks in five particle size ranges, namely, 0-74, $6274-125,125-180,180-224$ and 224-280 $\mu \mathrm{m}$. Saleh and Nugroho (2013) studied the effect of particle size on 63 spontaneous combustion of coal in the size groups of $-599+299,-299+249,-249-150,-150+76$ and-76 $\mu \mathrm{m}$ and 64 observed that the propensity of coal to spontaneous combustion increases with decreasing particle size. In view of 65 this, understanding of the characteristics, especially the particle size distribution and surface area, finds an important 66 place in the application and implications of pulverized coal in mining and allied industries.

67 Coal is a complex and highly porous material with 'sponge-like' structure. It contains numerous 68 interconnecting pores of different shapes and sizes. The specific surface area (i.e., surface area per unit mass, $\mathrm{m}^{2} / \mathrm{g}$ ) 69 of coal particles depends upon the method of its measurement, such as particle sizing, photoextinction, methylene 70 blue dye adsorption and gas adsorption (both noble gas and $\mathrm{CO}_{2}$ ). Among all the methods, particle size-based 71 measurement is most readily visualized as being the 'easily' accessible coal surface, since the specific surface area is 72 measured based on the average sieve size of the particles in the coal powder (Linge, 1989). The laser scattering 73 instruments are widely used for this purpose. In particle sizing by laser diffraction technique, the particle size and 74 specific surface area (S) are related as (ISO 13320-1: 2009)

$$
S=\frac{6 \sum \frac{V_{i}}{d_{i}}}{\rho \sum V_{i}}=\frac{6}{\rho D_{s}}
$$


where, $V_{i}$ is the relative volume by particle size class $d_{i}, \rho$ is the material density and $D_{s}$ is the mean

77 diameter based on surface area, also known as Sauter mean diameter. The above equation relates the specific surface

78 area of a collection of smooth spherical particles with the average diameter of an equivalent spherical particle $\left(D_{s}\right)$ of

79 density $(\rho)$.

80 Gas adsorption is the preferred technique for specific surface area determination, as it takes into account the

81 surface roughness and crevices of particle exterior and porous interior of the particles. Among several methods

82 developed, Brunauer-Emmett-Teller (BET) adsorption method (Brunauer et al., 1938) is commonly used to measure

83 the specific surface area of particulate matter by physisorption of $\mathrm{N}_{2}$ gas molecules at the boiling point temperature

84 of liquid nitrogen of about $77 \mathrm{~K}\left(-196^{\circ} \mathrm{C}\right)$ ) (Clarkson and Bustin, 1999; Cheng et al., 2015; Zhao et al., 2016).

85 The volume of gas adsorbed on a monolayer over the particles surface is determined as per the BET

86 isotherm equation (Brunauer et al., 1938)

$$
\frac{p}{v\left(p_{0}-p\right)}=\frac{1}{v_{m} c}+\frac{c-1}{v_{m} c}\left(\frac{p}{p_{0}}\right)
$$

88 where, $p$ and $p_{0}$ are the equilibrium and saturation pressure of adsorbate gas, $\frac{p}{p_{0}}$ is the relative pressure, $v$ is the

89 total volume of absorbed gas, $v_{\mathrm{m}}$ is the volume of gas required to form a complete unimolecular adsorbed layer, and

$90 \mathrm{c}$ is the BET constant. In Eq. (2), the plot of $\frac{p}{v\left(p_{0}-p\right)}$ against $\frac{p}{p_{0}}$ is a straight line, whose intercept is $\frac{1}{v_{m} c}$ and

91 slope is $\frac{c-1}{v_{m} c}$. The constants $v_{\mathrm{m}}$ and $c$ can be evaluated from the slope and intercept. In BET method, the specific

92 surface area $(S)$ of solid particles is determined by dividing the total surface area $\left(S_{\text {total }}\right)$ by mass of the solid sample

93 or adsorbent $(w)$. It is given by equation (Thommes et al., 2015)

$$
S=\frac{S_{\text {total }}}{w}
$$

$$
S_{\text {total }}=\frac{\left(v_{m} N A_{c s}\right)}{v}
$$
Avogadro's number $\left(6.023 \times 10^{23} \mathrm{~mol}^{-1}\right), A_{\mathrm{cs}}$ is the cross-sectional area of the adsorbate $\left(16.2 \AA^{2}\right.$ for nitrogen). 
BET method assumes that the particles usually are neither spherical nor smooth and it takes into account

99 the surface area of internal pore spaces. Conversely, particle sizing method assumes the particles as smooth,

100 spherical and nonporous. Therefore, the specific surface area measured by gas adsorption (BET method) is greater

101 than that measured by the laser diffraction instruments (Zlochower et al., 2018).

102 Several researchers have measured the particle size and specific surface area of different types of

103 pulverized coals using various methods (Table 1). From the table, it may be observed that $\mathrm{N}_{2}$ gas adsorption is the

104 most commonly used method among the others. Linge (1989) compared the surface area of coal particles measured

105 by different methods, including, particle sizing, photoextinction, methylene blue dye adsorption and gas adsorption

106 (both $\mathrm{N}_{2}$ and $\mathrm{CO}_{2}$ ). For the coal particles in size range of $15-9 \mu \mathrm{m}$, he reported the specific surface area by particle

107 sizing and $\mathrm{N}_{2}$ gas adsorption methods in the ranges of 0.16-0.30 and 1-7 $\mathrm{m}^{2} \mathrm{~g}^{-1}$, respectively. Cheng et al. (2015)

108 studied the effect of different experimental conditions on the specific surface area calculation and reported that BET

109 theory more accurately calculates the specific surface area of coal. Dubois et al. (2011) studied the dependency of

110 BET surface area on particle size for some granitic minerals of different particle sizes. They observed a linear

111 relationship between the BET surface area and inverse of the particle size, up to a certain particle size.

\section{Table 1}

113 This paper aims at investigating the (1) important physico-chemical properties of pulverized coals, such as

114 proximate and ultimate analyses, morphology, bulk density, particle size and specific surface area, (2) effect of

115 particle size on bulk density, specific surface area and $\mathrm{N}_{2}$ adsorption capacity of pulverized coals and (3)

116 establishing possible correlations among these parameters. Nine different Indian pulverized coals in five different

117 size ranges were considered in this study. The outcome of this study can have applications in the safety and risk

118 engineering of coal mines, process industries and utilities sector dealing with pulverized coals, and serve as

119 reference material for further researches on combustion and explosion involving coal dusts.

\section{2. Materials and Methods}

1232.1 Collection and preparation of coal samples

124 In this study, nine coal samples (A, B, C, D, E, F, G, H, I) collected from different coal mining companies situated 125 in different parts of India were used. The coal samples were pulverized in a dry ball mill and screened into five 
126 different particle size ranges, viz. <38, 38-74, 74-212, 212-425 and 425-850 $\mu \mathrm{m}$, using a series of sieves for

127 experimentation (Fig. 1). The morphology of pulverized coals was assessed using FE-SEM Supra 55 (Carl Zeiss,

128 Germany).

Fig. 1

1302.2 Proximate and ultimate analyses of coal

131 The proximate analysis of collected coal samples was done with a Thermogravimetric Analyzer (TGA-2000A,

132 Navas Instruments, USA) according to ASTM D7582 for determining the moisture (M), volatile matter (VM), ash

133 (A) and fixed carbon (FC) contents of coal samples. The ultimate analysis of coal samples was done using 'Flash

134 2000' Organic Elemental Analyzer (Thermo Scientific) as per ASTM D3176-15 for determining the elemental

135 composition of coal, such as carbon $(\mathrm{C})$, hydrogen $(\mathrm{H})$ nitrogen $(\mathrm{N})$ and oxygen $(\mathrm{O})$ contents.

136

1372.3 Measurement of bulk density of pulverized coals

138 The bulk density of coal is influenced by its physical characteristics, such as relative density, shape, particle size

139 distribution, surface properties and moisture content, and on the dimensions of the measuring container. The bulk

140 density of pulverized coals was determined using a fixed volume stainless steel container as per ISO 23499:2013, to

141 study the effect of particle size on bulk density of coal. Sufficient amount of coal powder was filled in the container

142 and compacted. Excess coal powder was scraped carefully from top of the vessel with the sharp edge of a spatula

143 and the weight of the coal powder in the container was taken. The bulk density of the sample was determined by

144 dividing the sample weight by container volume. The bulk density of each sample was determined thrice and the 145 average value was considered as the bulk density of the sample.

147 2.4 Measurement of particle size and specific surface area of pulverized coals

148 The particle size of pulverized coals of different sizes was determined with a particle size analyzer. However, the 149 specific surface area was determined using both particle size analyzer and surface characterization analyzer 150 utilizing multipoint Brunauer-Emmett-Teller (BET) method.

151 
153 The particle size distribution and specific surface area of pulverized coal samples were determined using Microtrac

154 S3500 Particle Size Analyzer system (Microtrac, USA) on dry basis in air entrainment mode operation. The 155 analyzer works on the principle of light scattering and utilizes three precisely placed red laser diodes to accurately

156 characterize particles as a volume equivalent sphere diameter in size range of 0.02 to $2800 \mu \mathrm{m}$. The device

157 measures the light scattered from the particles in a laser beam of wavelength $780 \mathrm{~nm}$. It analyses the intensity and

158 angle of light scattered from the particles measured by optical detector arays to determine the particle size

159 distribution based on algorithms that utilize Mie compensation and Modified Mie calculations for non-spherical 160 particles. In this study, the refractive index of coal was taken as 1.6 for particle size analysis (Mengüç et al., 1994).

161

162 2.4.2 Measurement by BET method

163 In this study, the BET surface area of pulverized coals was determined using $\mathrm{N}_{2}$ adsorption at $77 \mathrm{~K}$ with a 3Flex

1643500 high resolution surface characterization analyzer (Micromeritics, USA). This method utilizes the fact that the 165 extent of $\mathrm{N}_{2}$ adsorption is directly related to the available surface area. Prior to the adsorption experiments, 166 degassing of the coal samples was done at $130^{\circ}$ for almost 12 hours using sample degas system (Micromeritics 167 Vac Prep 061) to remove the volatile substances from the coal. Then the samples were kept in the liquid $\mathrm{N}_{2}$ 168 canister for almost 2 hours for saturated adsorption of $\mathrm{N}_{2}$ on available coal surfaces. The $\mathrm{N}_{2}$ adsorption isotherms 169 were captured at a relative pressure $\left(p / p_{0}\right)$ range of 0.05 to 0.3 .

\section{3. Results and Discussion}

$173 \quad 3.1$ Results of proximate and ultimate analyses

174 The results of proximate and ultimate analyses of coal samples are presented in Table 2 . The proximate analysis

175 results show that the moisture, volatile matter, ash and fixed carbon contents of the coals varied in the ranges of $1761.12-8.06,19.27-37.2,14.23-36.61$ and $22.97-58.54 \%$, respectively. The results of ultimate analysis show that the 177 carbon, hydrogen, nitrogen and oxygen contents of the coal samples varied in the ranges of 36.01-63.34, 3.06-4.51, 178 1.29-2.71 and 30.41-59.32\%, respectively. Moisture is an important parameter affecting the handling, storage and 
179 transport of coal. The VM content greatly influences the thermochemical reactivity and rank of coal (Speight, 2015).

180 The coal samples A, B, G and I possess lower VM content of 19.27, 21.1, 23.86 and $26.11 \%$, respectively, which

181 indicates their better storage potential and lower spontaneous combustion propensity (Nyakuma et al., 2017).

Table 2

183 The fuel ratios (ratio between the FC and VM) of coal samples were calculated to determine the rank of

184 coals. Based on the fuel ratio (FR), Frazer (1877) classified the coals as: Anthracite (FR: 12-100), Semi-anthracite

185 (FR: 8-12), Semi-bituminous (FR: 5-8) and bituminous (FR: 0-5). Since the fuel ratios of the coal samples

186 determined in the range of 0.62-2.8, the coals are confirmed to be of bituminous rank.

188 3.2 Morphology of pulverized coals

189 The micrographs of pulverized coals of different sizes, viz. $<38,38-74,74-212,212-425$ and 425-850 $\mu$ m, examined 190 with FE-SEM Supra 55 (Carl Zeiss, Germany) are presented in Fig. 2. The micrographs revealed that the coal 191 particles are mostly irregular in shape with angular outlines and sharp edges. Particle agglomeration and sticking of

192 fine particles with the coarser ones were also observed in the micrographs.

Fig. 2

1943.3 Effect of particle size on bulk density of pulverized coals

195 The variations of bulk density of different pulverized coal samples with particle size are shown in Fig. 3. The results

196 show that the bulk density of pulverized coals increases with increase in the particle size. Among all the samples, the

197 highest and lowest bulk density values were determined for samples $\mathrm{H}$ and $\mathrm{D}$, respectively. While the bulk density

198 of pulverized coals of $<38 \mu \mathrm{m}$ size varied in the range of $0.39-1.05 \mathrm{~g} / \mathrm{cm}^{3}$, for coals of $425-850 \mu \mathrm{m}$ size, it varied in

199 the range of $0.76-1.35 \mathrm{~g} / \mathrm{cm}^{3}$. The variations in bulk density of different pulverized coals of same particle size may

200 be due to the difference in coal properties. The mean bulk density of nine pulverized coals of sizes $<38,38-74,74-$

$201212,212-425$ and $425-850 \mu \mathrm{m}$ were determined $0.63 \pm 0.24,0.71 \pm 0.23,0.84 \pm 0.21,0.92 \pm 0.21$ and $0.97 \pm 0.22 \mathrm{~g} / \mathrm{cm}^{3}$,

202 respectively.

Fig. 3 
The variation of average bulk density of pulverized coals with particle size shown in Fig. 4 depicts an 205 increasing trend, which best fitted the polynomial trend with $\mathrm{R}^{2}=0.989$. The polynomial regression equation 206 obtained between the bulk density and particle size $\left(y=-0.007 x^{2}+0.136 x+0.492\right)$ in Fig. 4 can be used to predict 207 the bulk density of pulverized coals of known sizes. The average bulk density of pulverized coals increased from 2080.63 to $0.97 \mathrm{~g} / \mathrm{cm}^{3}$, or increased by 1.54 times, with increase in the particle size from $<38$ to $425-850 \mu \mathrm{m}$. The 209 reason behind decrease in bulk density with decrease in the particle size is attributed to the fact that with decrease in 210 particle size, the total surface area and voids between the particles are increased, which results in decrease of bulk 211 density due to increase in the volume of coal particles (Braga et al., 2019). Elliott (1981) and Braga et al. (2019) also 212 demonstrated that for the same moisture content, bigger coal particles have higher bulk density. Moreover, in the 213 coal particles of higher size range, the inert petrographic materials having higher hardness and resistance to crushing 214 are concentrated and thus, the bulk density of pulverized coals increases with increase in the particle size (Silva et 215 al., 2011). Sadovnikov and Gusev (2018) also observed decrease in the pycnometric density and increase in the 216 specific surface area with decrease in the average particle size of silver sulfide powders.

Fig. 4

2183.4 Effect of particle size on specific surface area of pulverized coals

219 The median particle diameter $\left(\mathrm{D}_{50}\right)$ and specific surface area of pulverized coals of different sizes determined by 220 particle sizing method are presented in Table 3. The particle size distribution curves of a coal sample for different 221 sizes are shown in Fig. 5. The $\mathrm{D}_{50}$ values of coal particles of $<38,38-74,74-212,212-425$ and $425-850 \mu \mathrm{m}$ were 222 determined in the ranges of 20.37-36.9, 39.07-57.57, 117.2-170.4, 343.3-386.0 and 763.3-837.3 $\mu \mathrm{m}$, with mean 223 values of $29.58 \pm 4.99,50.56 \pm 6.74,153.2 \pm 18.78,359.36 \pm 13.15$ and $802.28 \pm 28.58 \mu \mathrm{m}$, respectively. The specific 224 surface area of coal particles of $\langle 38,38-74,74-212,212-425$ and $425-850 \mu \mathrm{m}$ were determined in the ranges of $2250.239-0.423,0.163-0.338,0.043-0.112,0.017-0.035$ and $0.007-0.01 \mathrm{~m}^{2} / \mathrm{g}$, with mean values of $0.332 \pm 0.052$, $2260.234 \pm 0.051,0.066 \pm 0.027,0.021 \pm 0.006$ and $0.008 \pm 0.001 \mathrm{~m}^{2} / \mathrm{g}$, respectively.

Table 3

Fig. 5

229 The variations of median particle diameter $\left(D_{50}\right)$ and specific surface area of pulverized coals with particle 230 size are shown in Fig. 6. Similarly, the variations of average $\mathrm{D}_{50}$ and average specific surface area of pulverized 
231 coals with particle size are depicted in Fig. 7. From these figures, it is evident that $\mathrm{D}_{50}$ increases with increase in the 232 coal particle size. Generally, the specific surface area of pulverized coals increased with decrease in the particle size.

233 With decrease in particle size from $425-850$ to $<38 \mu \mathrm{m}$, the mean value of $\mathrm{D}_{50}$ decreased by 27 times and the mean

234 specific surface area increased by 41.5 times. The finer coal particles with greater exposed surface area interact more 235 with oxygen resulting in higher oxygen adsorption. Moreover, size reduction of coal due to crushing generates more 236 free radicals and accelerates the coal oxidation reactivity (Xu et al., 2020). Therefore, the finer coal particles are 237 more prone to spontaneous combustion. Moreover, they require lesser ignition energy and consequently, increase the 238 severity of coal dust explosion in mines (Mishra and Azam, 2018).

\section{Fig. 7}

241 In order to establish relationship between the specific surface area and particle size of pulverized coals, a 242 graph between the average median particle size $\left(D_{50}\right)$ and average specific surface area was plotted as shown in Fig.

243 8. It may be observed that the specific surface area of pulverized coals decreased with increase in the particle size, 244 exhibiting an asymptotic trend for particles beyond $350 \mu \mathrm{m}$. Sadovnikov and Gusev (2018) and Gómez-Tena et al. 245 (2014) also observed a similar trend. A good correlation $\left(R^{2}=0.994\right)$ was observed between the specific surface 246 area $(\mathrm{S})$ and median particle size $\left(\mathrm{D}_{50}\right)$ of pulverized coals, and the relationship obtained is given by

$$
\mathrm{S}=18.39\left(\mathrm{D}_{50}\right)^{-1.14}
$$

This equation can be used for predicting the specific surface area of pulverized coals of known median size.

2503.5 Effect of particle size on BET surface area and $\mathrm{N}_{2}$ adsorption capacity of pulverized coals

251 The BET surface areas $\left(\mathrm{S}_{\mathrm{BET}}\right)$ of pulverized coals $(\mathrm{A}, \mathrm{H}$ and $\mathrm{I})$ were measured in order to compare the specific 252 surface areas determined by both the particle sizing and BET methods, and the results are presented in Table 4. The 253 BET method includes the pore and external areas to compute the total specific surface area and provides critical 254 information regarding the effects of particle size and porosity on $\mathrm{N}_{2}$ adsorption and specific surface area.

Table 4 
The $\mathrm{N}_{2}$ adsorption isotherms of pulverized coal samples of $\mathrm{A}, \mathrm{H}$ and I for different particle sizes are

257 presented in Fig. 9. From the figure it is evident that $\mathrm{N}_{2}$ adsorption capacity of coals increases with decrease in the 258 particle size. It means, the finer coal particles adsorb greater quantity of $\mathrm{N}_{2}$ molecules than the coarser ones. Similar 259 phenomenon was also observed by other researchers (Dudzińska et al., 2017; Hou et al., 2017).

\section{Fig. 9}

The variations of BET surface area and monolayer $\mathrm{N}_{2}$ adsorption capacity with particle size of different 262 pulverized coals of samples A, H and I are shown in Fig. 10. With decrease in particle size from 425-850 to $<38 \mu \mathrm{m}$,

263 the $\mathrm{N}_{2}$ adsorption of coal samples $\mathrm{A}, \mathrm{H}$ and I increased from 0.0513 to $0.6438,0.7218$ to 0.9063 and 0.0341 to $2640.4439 \mathrm{~cm}^{3} / \mathrm{g}$, or in other words, it increased by $12.55,1.26$ and 13.02 times, respectively. This may be attributed to 265 the fact that as the particle size of coal increases, the mesopores get confined by more constricted pore openings and 266 thereby, reducing the accessibility of mesopores to the $\mathrm{N}_{2}$ molecules. These constrictions are removed with decrease 267 in particle size by comminution, and consequently, increasing the pore accessibility to $\mathrm{N}_{2}$ molecules (Cui et al., 268 2004; Chen et al., 2015; Hou et al., 2017). Thus, with size reduction of coal during mining process, the propensity of 269 coals to spontaneous combustion enhances due to sorption of greater amount of oxygen on the coal surface. Xiumin 270 et al. (2002) reported that when the coal particle size reduced from 83.77 to $19.30 \mu \mathrm{m}$, the BET surface area 271 increased by 20.81 times. They explained, the main reasons for increase in the specific surface area with decrease in 272 coal particle size are due to the decrease in average pore diameter and exposure of more and more small pores 273 within the particles.

Among the three samples, $\mathrm{N}_{2}$ sorption was found to be high in sample $\mathrm{H}$, medium in samples A and low in

275 sample I. This suggests that sample $\mathrm{H}$ is of high porous structure and easily accessible to $\mathrm{N}_{2}$ molecules as compared 276 to the samples A and I.

Figure 10 also depicts that the variation of BET surface area with coal particle size is consistent with the $\mathrm{N}_{2}$

279 adsorption. BET surface area increased with decrease in the particle size of coal. With decrease in particle size from $280425-850$ to $<38 \mu \mathrm{m}$, the BET surface area for coal samples A, H and I increased from 0.22 to $2.80,3.14$ to 3.94 and 2810.15 to $1.93 \mathrm{~m}^{2} / \mathrm{g}$, or in other words, it increased by $12.73,1.25$ and 12.87 times, respectively. A similar trend was 282 also reported by other researchers. Hou et al. (2017) determined the BET specific surface area of original coal and 
283 tectonized coal in five particle size fractions, i.e., 500-1000, 250-500, 125-250, 63-125 and 32-63 $\mu \mathrm{m}$, and

284 observed an increase in surface area from 0.22 to 3.06 and 1.00 to $2.07 \mathrm{~m}^{2} / \mathrm{g}$ in original coal and tectonized coal,

285 respectively with decrease in particle size. The BET surface area decreased in the order of coal samples $\mathrm{H}>\mathrm{A}>\mathrm{I}$,

286 irrespective of the particle size. The high specific surface area of sample H may be attributed to its high porosity

287 (Dudzińska et al., 2017).

288 Hou et al. (2017) reported that the decrease in particle size makes some inaccessible mesopores accessible

289 to $\mathrm{N}_{2}$ molecules and increases the mesopore specific surface area and volume. In contrast to mesopore

290 characteristics, the micropore characteristics are independent of particle size. Liu et al. (2010) also observed that the

291 BET specific surface area increases with decreases in the coal particle size, while the mean pore size shows an

292 approximately opposite trend. The reason they cited for this is that, when the particle diameter is reduced, more and

293 more small pores inside the matrix are exposed, resulting in the increase of specific surface area.

294 3.6 Comparison between particle sizing and BET surface areas

295 A comparative analysis of surface areas of coal particles determined by both the particle sizing and BET methods

296 was done as shown in Fig. 11. It may be observed that the specific surface areas of coal samples determined by both

297 the methods decrease in the order $\mathrm{H}>\mathrm{A}>\mathrm{I}$. Among the three samples, the specific surface area of sample $\mathrm{H}$ was

298 found to be highest in all the particle sizes. This indicates that sample $\mathrm{H}$ is highly porous in nature among the three 299 samples.

Fig. 11

301 An attempt was also made to find the relationships and determine correlation factors between the specific

302 surface areas determined by both the particle sizing and BET methods (Fig. 12). Good linear correlation between the

303 specific surface area values determined by both the methods was observed. In case of samples A and I, the

304 correlation factor was determined about 7 and 5, respectively, which means the BET specific surface area is

305 approximately 7 and 5 times, respectively greater than the particle sizing surface area. Gómez-Tena et al. (2014)

306 determined correlation factor of 6 for ceramic materials. In contrast, in case of sample $\mathrm{H}$, though a good correlation

307 was observed between the surface area values measured by both the methods, the correlation factor was found to be

308 approximately 2 with a greater y-intercept of 3.17. The deviation signifies the highly porous nature of the sample. It 
309 is worth mentioning here that the correlation between the specific surface areas determined by both the methods

310 depends on the characteristics of the coal, and especially on the coal particle size and porosity. The correlation

311 factors determined in this study are specific to the coals analyzed and can be used as a reference for comparison

312 purpose by other studies.

\section{4. Conclusions}

315 Characterization of coal finds an important place in researches concerning spontaneous combustion of coal and coal

316 dust explosion aiming at safety of coal mines, process industries and utilities sector. This study investigated the

317 physico-chemical properties, such as proximate and ultimate analyses, particle morphology, bulk density, particle

318 size, specific surface area and $\mathrm{N}_{2}$ adsorption capacity of pulverized coals at five distinct size ranges. The moisture,

319 volatile matter, ash and fixed carbon contents of coals varied in the ranges of 1.12-8.06, 19.27-37.2, 14.23-36.61 and

$32022.97-58.54 \%$, respectively, and the carbon, hydrogen, nitrogen and oxygen contents of coals varied in the ranges of

$32136.01-63.34,3.06-4.51,1.29-2.71$ and $30.41-59.32 \%$, respectively. The coal particles are mostly found to be

322 irregular in shape with angular outlines and sharp edges. Interesting results with respect to the variations of bulk

323 density, specific surface area and $\mathrm{N}_{2}$ adsorption capacity of pulverized coals with particle size were obtained. The

324 study revealed that the bulk density, specific surface area and $\mathrm{N}_{2}$ adsorption capacity of pulverized coals greatly

325 influenced by the particle size. The bulk density of pulverized coals increased with increase in the particle size. The

326 bulk density of the smallest $(<38 \mu \mathrm{m})$ and coarsest size $(425-850 \mu \mathrm{m})$ coals varied in the ranges of $0.39-1.05 \mathrm{~g} / \mathrm{cm}^{3}$

327 and $0.76-1.35 \mathrm{~g} / \mathrm{cm}^{3}$, respectively. With increase in the particle size from $<38$ to $425-850 \mu \mathrm{m}$, the average bulk

328 density of pulverized coals increased from 0.63 to $0.97 \mathrm{~g} / \mathrm{cm}^{3}$, or it increased by 1.54 times. The polynomial

329 regression equation obtained between the bulk density and particle size $\left(y=-0.007 x^{2}+0.136 x+0.492\right)$ can be used

330 to predict the bulk density of pulverized coals of known sizes.

331 The specific surface area of pulverized coals increased with decrease in the particle size. With decrease in

332 particle size from $425-850$ to $<38 \mu \mathrm{m}$, the mean $\mathrm{D}_{50}$ value decreased by 27 times and the mean specific surface area

333 increased by 41.5 times. The relationship obtained between the specific surface area (S) and median particle size

$334\left(\mathrm{D}_{50}\right)$ of pulverized coals $\left[\mathrm{S}=18.39\left(\mathrm{D}_{50}\right)^{-1.14}\right]$ can be used to predict the specific surface area of pulverized coals of

335 known median size. The monolayer adsorption of $\mathrm{N}_{2}$ and BET surface area increased with decrease in the particle 
336 size of pulverized coals. With decrease in particle size from $425-850$ to $<38 \mu \mathrm{m}$, the BET surface area for coal

337 samples of A, H and I increased from 0.22 to $2.80,3.14$ to 3.94 and 0.15 to $1.93 \mathrm{~m}^{2} / \mathrm{g}$, or it increased by $12.73,1.25$

338 and 12.87 times, respectively. This signifies that the finer coal particles are more prone to spontaneous combustion

339 and explosion due to exposure of greater surface area for oxygen sorption. Linear correlation was obtained between

340 the particle sizing and BET specific surface areas of pulverized coals. In case of samples A, H and I, the correlation

341 factors between the particle sizing and BET specific surface areas were determined 7, 2 and 5, respectively.

342

343

\section{Acknowledgment}

344 The financial support received for this study from the Science and Engineering Research Board (SERB), Govt. of 345 India [No. EMR/2016/004210] is greatly acknowledged.

346

\section{Declarations}

\section{Ethical approval:}

349 Not applicable. This research does not involve the use of any animal or human data or tissue.

\section{Consent to Participate:}

352 Not applicable.

353

\section{Consent to Publish:}

355 Not applicable.

356

\section{Author Contributions:}

358 D. P. Mishra: Conceptualization, Methodology, Data curation, Formal analysis and investigation, Writing - original

359 draft preparation, Writing - review and editing, Funding acquisition, Project administration, Resources.

\section{Funding:}

362 This research was funded by Science and Engineering Research Board (SERB), Govt. of India [Grant No. 363 EMR/2016/004210]. 


\section{Competing interests:}

366 The author declares no competing interests.

\section{Availability of data and materials:}

369 All relevant data generated during the study are included in the article.

\section{References}

372 Amyotte, P.R., Basu, A. Khan, F.I., 2003. Reduction of dust explosion hazard by fuel substitution in power plants. Process Saf. Environ. Prot. 81:457-462. https://doi.org/10.1205/095758203770866629

Amyotte, P.R., Mintz, K.J., Pegg, M.J., Sun, Y.H., 1993. The ignitability of coal dust-air and methane-coal dust-air mixtures. Fuel 72:671-679. https://doi.org/10.1016/0016-2361(93)90580-U.

376

Azam, S., Mishra, D.P., 2019. Effects of particle size, dust concentration and dust-dispersion-air pressure on rock dust inertant requirement for coal dust explosion suppression in underground coal mines. Process Saf. Environ. Prot. 126:35-43. https://doi.org/10.1016/j.psep.2019.03.030.

Braga, E.M.H., da Silva, G.L.R., Amaral, R.C.V., Carias, M.C., 2019. Influence of moisture and particle size on coal blend bulk density. REM - Int. Eng. J. 72:237-242. https://doi.org/10.1590/0370-44672018720006.

Brunauer, S., Emmett, P.H., Teller, E., 1938. Adsorption of gases in multimolecular layers. J. Am. Chem. Soc. 60:309-319. https://doi.org/10.1021/ja01269a023.

Cao, W., Huang, L., Zhang, J., Xu, S., Qiu, S., Pan, F., 2012. Research on characteristic parameters of coal-dust explosion. Procedia Eng. 45:442-447. https://doi.org/10.1016/j.proeng.2012.08.183.

Cashdollar, K.L., 1996. Coal dust explosibility. J. Loss Prev. Process Ind. 9:65-76. https://doi.org/10.1016/09504230(95)00050-X.

Cashdollar, K.L., 2000. Overview of dust explosibility characteristics. J. Loss Prev. Process Ind. 13:183-199. https://doi.org/10.1016/S0950-4230(99)00039-X. 
389 Chen, Y.Y., Wei, L., Mastalerz, M., Schimmelmann, A., 2015. The effect of analytical particle size on gas adsorption porosimetry of shale. Int. J. Coal Geol. 138:103-112. http://dx.doi.org/10.1016/j.coal.2014.12.012.

392 Cheng, H., Wang, Q., Zhang, S., Guo, R., 2015. Effect of different experimental conditions on the specific surface

of coal. Coke

Chem. 58:284-289. https://doi.org/https://doi.org/10.3103/S1068364X15080086.

395 Clarkson, C.R., Bustin, R.M., 1999. Effect of pore structure and gas pressure upon the transport properties of coal: a laboratory and modeling study. 1. Isotherms and pore volume distributions. Fuel 78, 1333-1344. https://doi.org/10.1016/S0016-2361(99)00055-1.

Cui, X.J., Bustin, R.M., Dipple, G., 2004. Selective transport of $\mathrm{CO}_{2}, \mathrm{CH}_{4}$, and $\mathrm{N}_{2}$ in coals: insights from modeling of experimental gas adsorption data. Fuel 83:293-303. http://dx.doi.org/10.1016/j.fuel.2003.09.001.

400 Dubois, I.E., Holgersson, S., Allard, S., Malmström, M., 2011. Dependency of BET surface area on particle size for 401 some granitic minerals. Proc. Radiochem A Suppl to Radiochim Acta 1:75-82. https://doi.org/10.1524/rcpr.2011.0013.

403 Dudzińska, A., Howaniec, N., Smolinski, A., 2017. Effect of coal grain size on sorption capacity with respect to 404 propylene and acetylene. Energies 10, 1919. https://doi.org/10.3390/en10111919.

405 Elliott, M.A., 1981. Chemistry of coal utilization (Second supplementary volume), United States.

406 Frazer, P. Jr., 1877. Classification of coals. Am. Inst. Min. Eng. 6, 430.

407 Gao, C., Li, H., Su, D., 2010. Explosion characteristics of coal dust in a sealed vessel. Explos. Shock Waves 408 30:164-168.

409 Gómez Tena, M.P., Gilabert, J., Machí, C., Zumaquero, E., Toledo, J., 2014. Relationship between the specific surface area parameters determined using different analytical techniques. XII Foro Glob. Del Recubrimiento Cerámico. Qualicer, 1-10.

412 Harris, M.L., Sapko, M.J., Zlochower, I.A., Perera, I.E., Weiss, E.S., 2015. Particle size and surface area effects on 413 explosibility using a 20-L chamber. J. Loss Prev. Process Ind. 37:33-38. 414 https://doi.org/10.1016/j.jlp.2015.06.009. 
415 Hosseinzadeh, S., Berghmans, J., Degreve, J., Verplaetsen, F., 2019. A model for the minimum ignition energy of dust clouds. Process Saf. Environ. Prot. 121:43-49. https://doi.org/10.1016/j.psep.2018.10.004

417 Hou, S., Wang, X., Wang, X., Yuan, Y., Pan, S., Wang, X., 2017. Pore structure characterization of low volatile 418 bituminous coals with different particle size and tectonic deformation using low pressure gas adsorption. Int. J. Coal Geol. 183:1-13. https://doi.org/10.1016/j.coal.2017.09.013.

420 ISO 13320-1: 2009. Particle size analysis. Laser diffraction methods. Part 1: General principles.

421 ISO 23499:2013. Coal — Determination of bulk density for the use in charging of coke ovens.

422 Laney, A.S., Weissman, D.N., 2014. Respiratory diseases caused by coal mine dust. J. Occup. Environ. Med. 56, 423 S18-22. https://doi.org/10.1097/JOM.0000000000000260.

424 Li, B., Li, M., Gao, W., Bi, M., Ma, L., Qin, Q., Shu, C.M., 2020. Effects of particle size on the self-ignition 425 behaviour of a coal dust layer on a hot plate. Fuel 260, 116269. https://doi.org/10.1016/j.fuel.2019.116269.

426 Li, H., Deng, J., Chen, X., Shu, C.M., Kuo, C.H., Zhai, X., Wang, Q., Hu, X., 2020. Qualitative and quantitative 427 characterisation for explosion severity and gaseous-solid residues during methane-coal particle hybrid explosions: An approach to estimating the safety degree for underground coal mines. Process Saf. Environ. Prot. 141:150-166. https://doi.org/10.1016/j.psep.2020.05.033

430 Li, Q., Wang, K., Zheng, Y., Ruan, M., Mei, X., Lin, B., 2016. Experimental research of particle size and size dispersity on the explosibility characteristics of coal dust. Powder Technology 292:290-297. https://doi.org/10.1016/j.powtec.2016.01.035.

433 Linge, H.G., 1989. The surface area of coal particles. Fuel 68:111-113. https://doi.org/10.1016/00162361(89)90021-5.

435 Liu, J., Jiang, X., Huang, X., Wu, S., 2010. Morphological characterization of super fine pulverized coal particle. Part 4. Nitrogen adsorption and small angle x-ray scattering study. Energy and Fuels 24:3072-3085. https://doi.org/10.1021/ef100142t.

438 Liu, S.H., Cheng, Y.F., Meng, X.R., Ma, H.H., Song, S.X., Liu,W.J. et al., 2018. Influence of particle size polydispersity on coal dust explosibility. J Loss Prev. Process Ind. 56:444-450. https://doi.org/10.1016/j.jlp.2018.10.005. 
441 Mengüç, M.P., Manickavasagam, S., D’Sa, D.A., 1994. Determination of radiative properties of pulverized coal particles from experiments. Fuel 73:613-625. https://doi.org/10.1016/0016-2361(94)90048-5.

443 Mishra, D.P., Azam, S., 2018. Experimental investigation on effects of particle size, dust concentration and dust444 dispersion-air pressure on minimum ignition temperature and combustion process of coal dust clouds in a G$445 \quad$ G furnace. Fuel 227:424-433. https://doi.org/10.1016/j.fuel.2018.04.122.

446 Nyakuma, B., Oladokun, O., Jauro, A., Nyakuma, D., 2017. Fuel characterization of newly discovered nigerian 447 coals. IOP Conf. Ser. Mater. Sci. Eng., vol. 217, Institute of Physics Publishing. https://doi.org/10.1088/1757-899X/217/1/012012.

449 Pan, R., Qiu, T., Chao, J., Ma, H., Wang, J., Li, C., 2020. Thermal evolution of the oxidation characteristics of pulverized coal with different particle sizes and heating rates. Thermochimica Acta 685:1785162. https://doi.org/10.1016/j.tca.2020.178516.

Rifella, A., Setyawan, D., Chun, D.H., Yoo, J., Kim, S.D., Rhim, Y.J. et al., 2019. The effects of coal particle size on spontaneous combustion characteristics. Int. J. Coal Prep. Util., 1-25. https://doi.org/10.1080/19392699.2019.1622529.

455 Sadovnikov, S.I., Gusev, A.I., 2018. Effect of particle size and specific surface area on the determination of the 456 density of nanocrystalline silver sulfide $\mathrm{Ag}_{2} \mathrm{~S}$ powders. Phys. Solid State 60:877-881. https://doi.org/10.1134/S106378341805027X.

458 Saleh, M., Nugroho, Y.S., 2013. Thermogravimetric study of the effect of particle size on the spontaneous combustion of indonesian low rank coal. Appl. Mech. Mater. 330:101-105. https://doi.org/10.4028/www.scientific.net/AMM.330.101.

461 Silva, G.L.R., Destro, E., Marinho, G.M., Assis, P.S., 2011. Caracterização química, física e metalúrgica das frações granulométricas da mistura de carvão da Gerdau Açominas. In: SEMINÁRIO DE CARVÃO, 1. Gramado (Contribuição Técnica).

464 Speight, J.G., 2015. Handbook of coal analysis, John Wiley \& Sons, Inc. https://doi.org/10.1002/9781119037699.

465 Thommes, M., Kaneko, K., Neimark, A.V., Olivier, J.P., Rodriguez-Reinoso, F., Rouquerol, J. et al., 2015. 466 Physisorption of gases, with special reference to the evaluation of surface area and pore size distribution 
468 Xiumin, J., Chuguang, Z., Che, Y., Dechang, L., Jianrong, Q., Jubin, L., 2002. Physical structure and combustion 469 properties of super fine pulverized coal particle. Fuel 81:793-797.

470 Xu, Q., Yang, S., Yang, W., Tang, Z., Hu, X., Song, W., Zhou, B., 2020. Micro-structure of crushed coal with different metamorphic degrees and its low-temperature oxidation. Process Saf. Environ. Prot. 140:330-338.

473 Yong, S., Shugang, W., Lu, W., Cao, Y., Li, J., 2019. Coal spontaneous combustion characteristics based on constant temperature difference guidance method. Process Saf. Environ. Prot. 131:223-234. https://doi.org/10.1016/j.psep.2019.09.013

476 Yu, A.B., Standish, N., Lu, L., 1995. Coal agglomeration and its effect on bulk density. Powder Technology 82:177-189. https://doi.org/10.1016/0032-5910(94)02912-8.

478 Yuan, Z., Khakzad, N., Khan, F., Amyotte, P., 2015. Dust explosions: A threat to the process industries. Process Saf. Environ. Prot. 98:57-71. http://dx.doi.org/10.1016/j.psep.2015.06.008

480 Zhao, J., Xu, H., Tang, D., Mathews, J.P., Li, S., Tao, S., 2016. A comparative evaluation of coal specific surface area by $\mathrm{CO}_{2}$ and $\mathrm{N}_{2}$ adsorption and its influence on $\mathrm{CH}_{4}$ adsorption capacity at different pore sizes. Fuel

483 Zlochower, I.A., Sapko, M.J., Perera, I.E., Brown, C.B., Harris, M.L., Rayyan, N.S., 2018. Influence of specific 484 surface area on coal dust explosibility using the 20-L chamber. J. Loss Prev. Process Ind. 54:103-109. https://doi.org/10.1016/j.jlp.2018.03.004. 
487 Table 1. Particle size and specific surface area of pulverized coals measured by particle sizing and gas adsorption methods

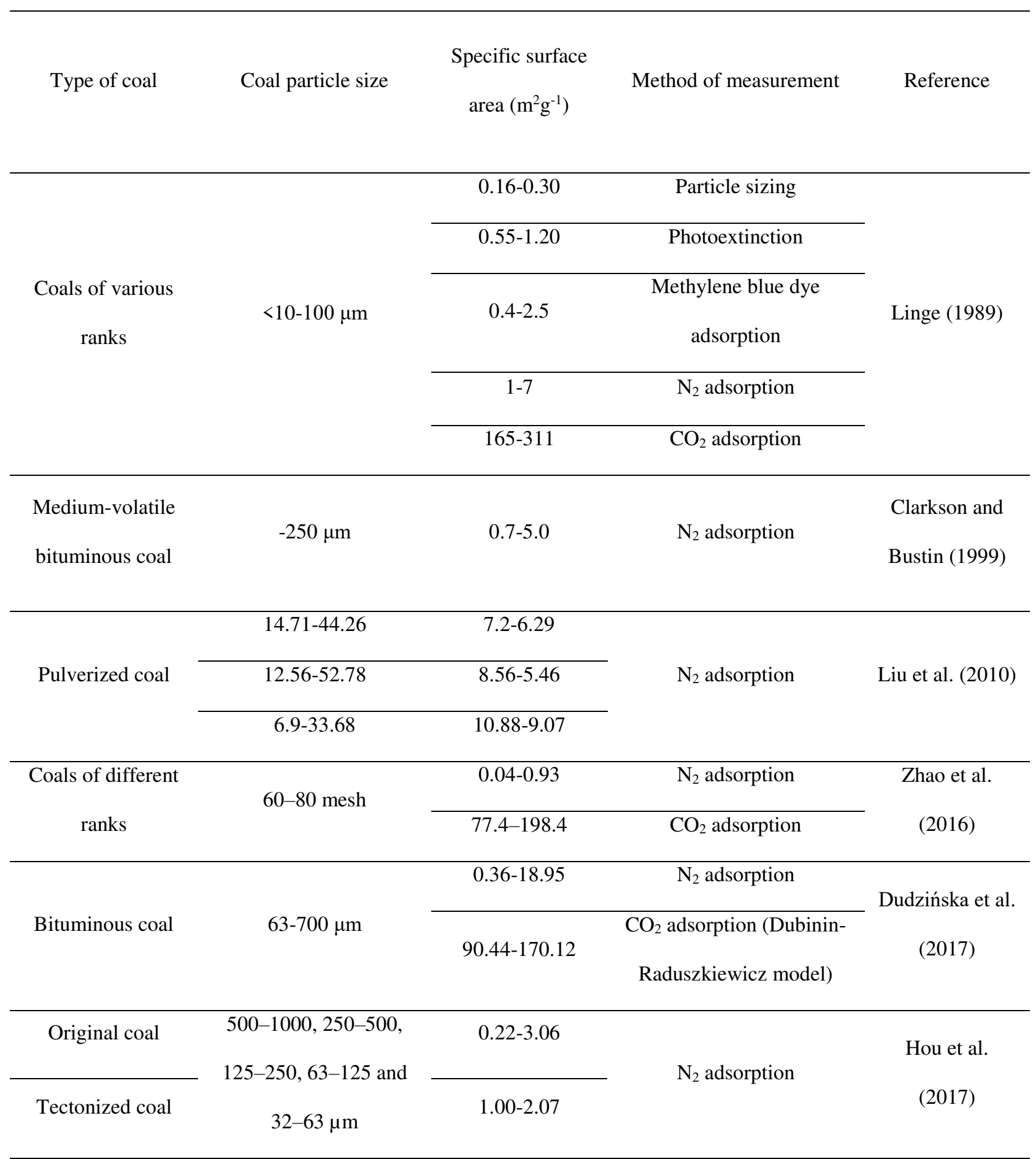


Mean particle diameter
Coal dust
$\left(\mathrm{D}_{50}\right)$ :
$2.76-0.04$
Laser particle size analyser Liu et al. (2018)
$5.42-190.46 \mu \mathrm{m}$

489

490

491

Table 2: Results of proximate and ultimate analysis of coal samples

\begin{tabular}{|c|c|c|c|c|c|c|c|c|c|}
\hline \multirow{2}{*}{ Coal sample } & \multicolumn{4}{|c|}{ Proximate analysis (w/w \%) } & \multirow{2}{*}{ Fuel ratio $(\mathrm{FC} / \mathrm{VM})$} & \multicolumn{4}{|c|}{ Ultimate analysis (w/w \%) } \\
\hline & $\mathrm{M}$ & $\mathrm{VM}$ & $\mathrm{A}$ & FC & & $\mathrm{C}$ & $\mathrm{H}$ & $\mathrm{N}$ & $\mathrm{O}$ \\
\hline $\mathrm{A}$ & 1.24 & 19.27 & 25.44 & 54.05 & 2.80 & 60.79 & 3.58 & 1.96 & 33.66 \\
\hline B & 1.63 & 21.1 & 36.61 & 40.66 & 1.93 & 36.01 & 3.06 & 1.61 & 59.32 \\
\hline $\mathrm{C}$ & 8.05 & 33.21 & 23.26 & 35.48 & 1.07 & 54.44 & 4.51 & 1.88 & 39.17 \\
\hline $\mathrm{D}$ & 4.33 & 36.82 & 35.88 & 22.97 & 0.62 & 44.28 & 3.57 & 1.65 & 50.51 \\
\hline $\mathrm{E}$ & 7.71 & 36.84 & 22.81 & 32.64 & 0.89 & 58.96 & 4.22 & 1.97 & 34.85 \\
\hline $\mathrm{F}$ & 5.88 & 30.82 & 20.88 & 42.42 & 1.38 & 58.00 & 3.54 & 2.71 & 32.47 \\
\hline G & 8.06 & 23.86 & 31.77 & 36.31 & 1.52 & 46.24 & 3.30 & 1.29 & 45.67 \\
\hline $\mathrm{H}$ & 6.63 & 37.2 & 14.32 & 41.85 & 1.13 & 63.34 & 4.13 & 2.12 & 30.41 \\
\hline I & 1.12 & 26.11 & 14.23 & 58.54 & 2.24 & 61.81 & 3.84 & 1.87 & 32.47 \\
\hline
\end{tabular}

492 M: moisture; VM: volatile matter; A: ash; FC: fixed carbon

493

494

Table 3: Median particle diameter and specific surface area of different sizes of pulverized coals

\begin{tabular}{ccccc}
\hline Particle size & \multicolumn{2}{c}{ Median particle diameter $\left(\mathrm{D}_{50}\right), \mu \mathrm{m}$} & \multicolumn{2}{c}{ Specific surface area, $\mathrm{m}^{2} / \mathrm{g}$} \\
\cline { 2 - 5 }$(\mu \mathrm{m})$ & Range & Mean $\pm \mathrm{SD}$ & Range & Mean $\pm \mathrm{SD}$ \\
\hline$<38$ & $20.37-36.9$ & $29.58 \pm 4.99$ & $0.239-0.423$ & $0.332 \pm 0.052$ \\
$38-74$ & $39.07-57.57$ & $50.56 \pm 6.74$ & $0.163-0.338$ & $0.234 \pm 0.051$ \\
$74-212$ & $117.2-170.4$ & $153.2 \pm 18.78$ & $0.043-0.112$ & $0.066 \pm 0.027$ \\
\hline
\end{tabular}




$\begin{array}{lrrrr}212-425 & 343.3-386.0 & 359.36 \pm 13.15 & 0.017-0.035 & 0.021 \pm 0.006 \\ 425-850 & 763.3-837.3 & 802.28 \pm 28.58 & 0.007-0.01 & 0.008 \pm 0.001\end{array}$

SD: Standard deviation

496

497

Table 4: BET specific surface area and monolayer adsorbed $N_{2}\left(Q_{m}\right)$ of pulverized coals of various sizes

\begin{tabular}{|c|c|c|c|c|c|c|}
\hline \multirow{3}{*}{ Particle size $(\mu \mathrm{m})$} & \multicolumn{2}{|c|}{ Sample A } & \multicolumn{2}{|c|}{ Sample H } & \multicolumn{2}{|c|}{ Sample I } \\
\hline & $\mathrm{S}_{\mathrm{BET}}$ & $\mathrm{Q}_{\mathrm{m}}$ & $\mathrm{S}_{\mathrm{BET}}$ & $\mathrm{Qm}_{\mathrm{m}}$ & $\mathrm{S}_{\mathrm{BET}}$ & $\mathrm{Q}_{\mathrm{m}}$ \\
\hline & $\mathrm{m}^{2} / \mathrm{g}$ & $\mathrm{cm}^{3} / \mathrm{g}$ & $\mathrm{m}^{2} / \mathrm{g}$ & $\mathrm{cm}^{3} / \mathrm{g}$ & $\mathrm{m}^{2} / \mathrm{g}$ & $\mathrm{cm}^{3} / \mathrm{g}$ \\
\hline$<38$ & 2.80 & 0.6438 & 3.94 & 0.9063 & 1.93 & 0.4439 \\
\hline $38-74$ & 1.33 & 0.3046 & 3.54 & 0.8143 & 0.82 & 0.1881 \\
\hline $74-212$ & 0.47 & 0.1075 & 3.39 & 0.7783 & 0.75 & 0.1724 \\
\hline $212-425$ & 0.24 & 0.0542 & 3.17 & 0.7293 & 0.60 & 0.1377 \\
\hline $425-850$ & 0.22 & 0.0513 & 3.14 & 0.7218 & 0.15 & 0.0341 \\
\hline
\end{tabular}

498

499 Figure captions

500 Fig. 1. Pulverized coal samples of various sizes

501 Fig. 2. SEM pictographs of pulverized coals of different sizes

502 Fig. 3. Variations of bulk density of different pulverized coal samples with particle size

503 Fig. 4. Variation of average bulk density of pulverized coals with particle size

504 Fig. 5. Particle size distributions of pulverized coals of different sizes: (a) $<38 \mu \mathrm{m}$, (b) $38-74 \mu \mathrm{m}$, (c) $74-212 \mu \mathrm{m}$,

505 (d) $212-425 \mu \mathrm{m}$ and (e) $425-850 \mu \mathrm{m}$

506 Fig. 6. Variations of $\mathrm{D}_{50}$ and specific surface area of pulverized coals with particle size

507 Fig. 7. Variations of average $D_{50}$ and specific surface area of pulverized coals with particle size 
508 Fig. 8. Relationship between the median particle size $\left(\mathrm{D}_{50}\right)$ and specific surface area of pulverized coals

509 Fig. 9. $\mathrm{N}_{2}$ gas adsorption isotherms of coal samples at different particle sizes: (a) Sample A, (b) Sample H, (c)

$510 \quad$ Sample I

511 Fig. 10. Variations of BET specific surface area and monolayer adsorbed $\mathrm{N}_{2}$ with particle size of different

$512 \quad$ pulverized coal samples

513 Fig. 11. Comparison between the particle sizing and BET specific surface areas of pulverized coal samples of $514 \quad$ different sizes

515 Fig. 12. Relationship between the particle sizing and BET specific surface areas of pulverized coals

516

517

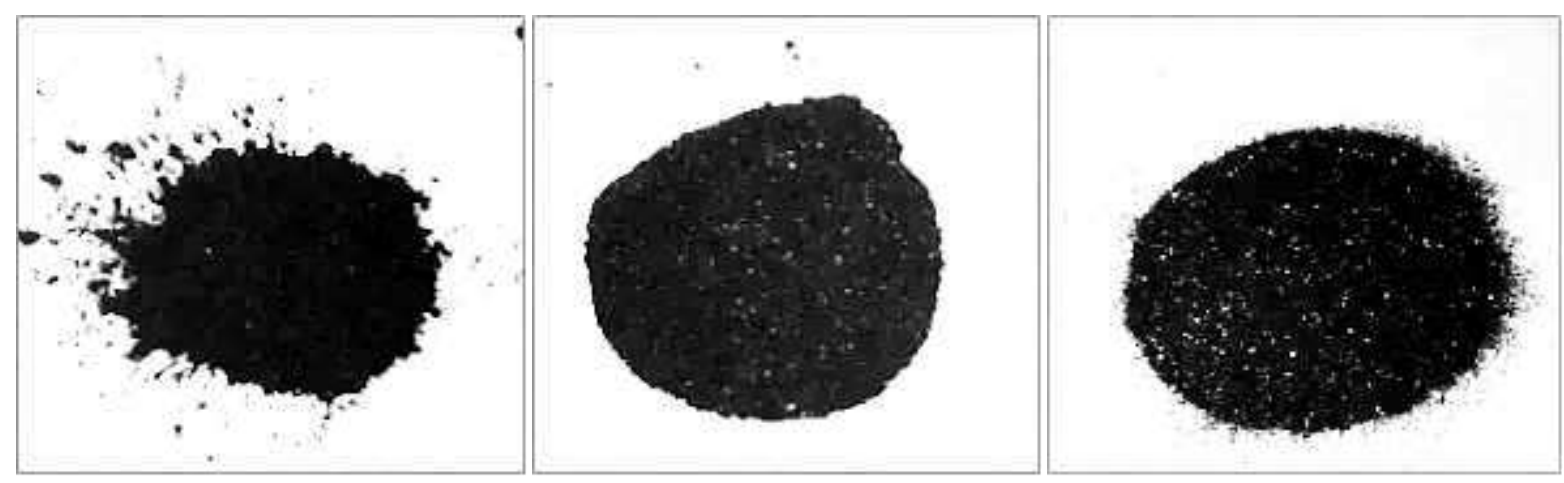

518

(a) $<38 \mu \mathrm{m}$

(b) $38-74 \mu \mathrm{m}$

(c) $74-212 \mu \mathrm{m}$
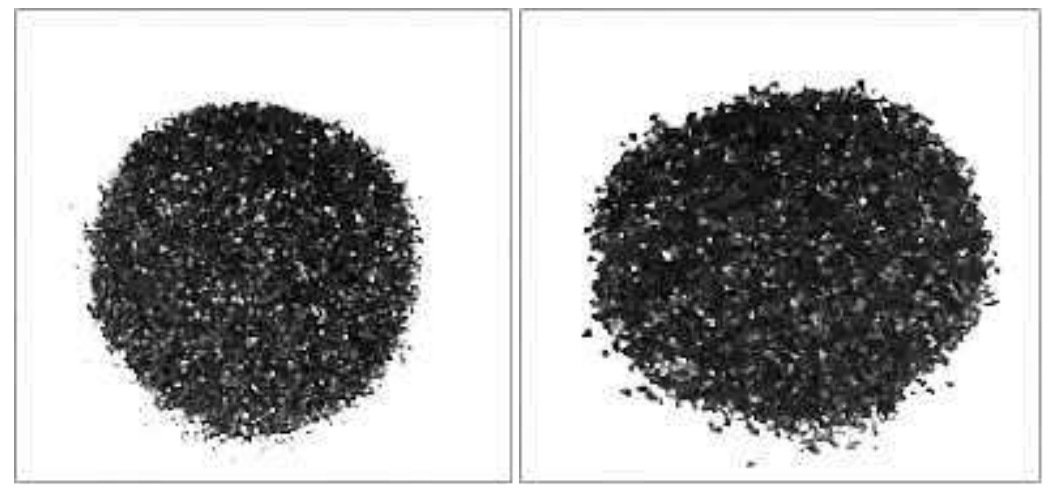

(d) $212-425 \mu \mathrm{m}$

(e) $425-850 \mu \mathrm{m}$

Fig. 1. 


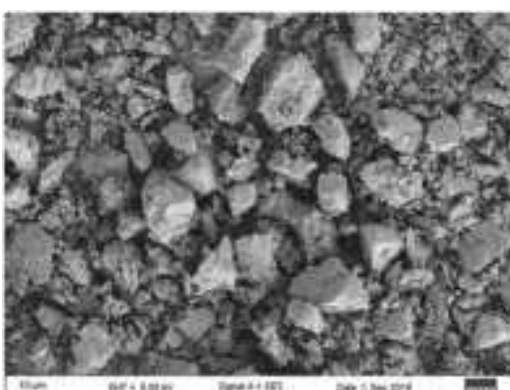

netinn

aexion

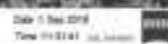

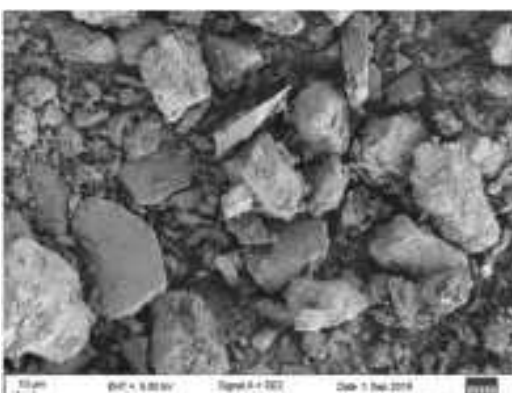

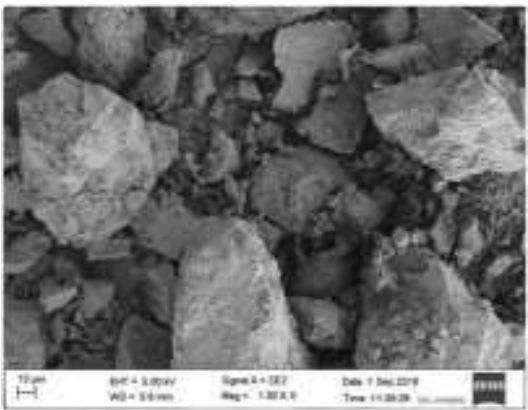

524

(a) $<38 \mu \mathrm{m}$

(b) $38-74 \mu \mathrm{m}$

(c) $74-212 \mu \mathrm{m}$
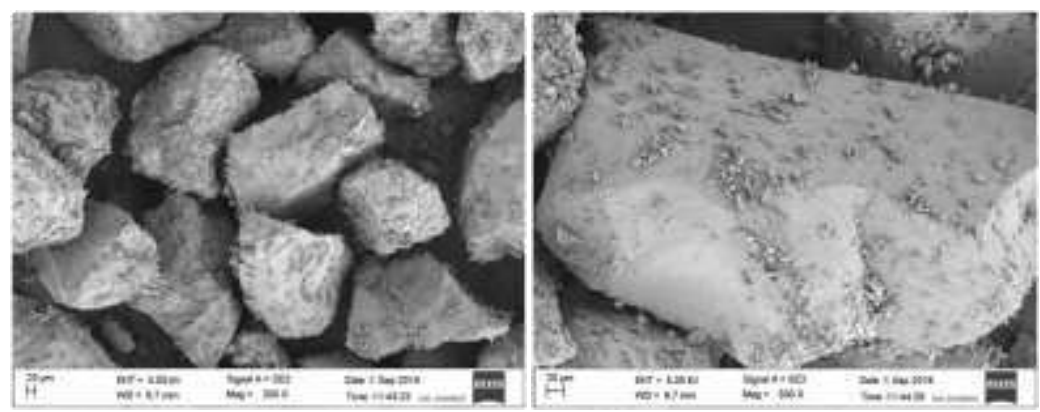

(d) $212-425 \mu \mathrm{m}$

(e) $425-850 \mu \mathrm{m}$

Fig. 2

\section{8}

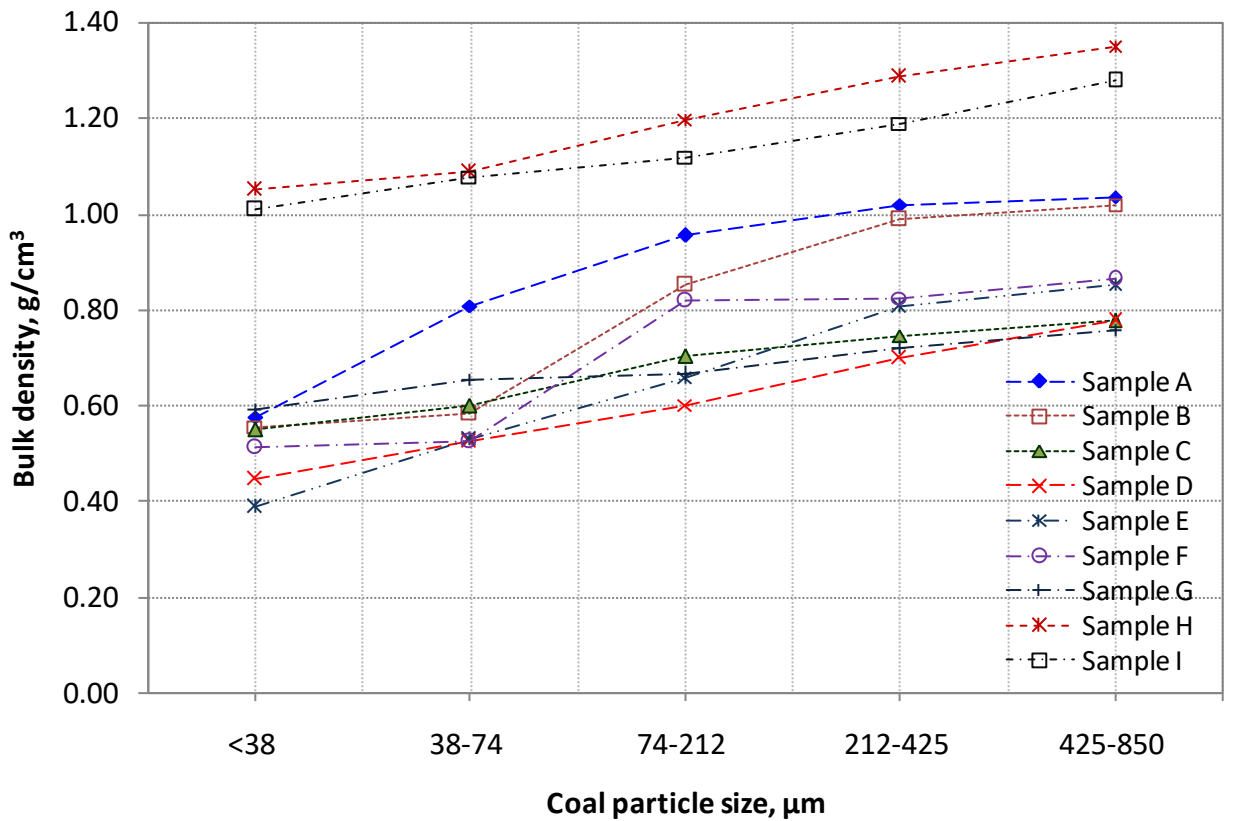

Fig. 3. 


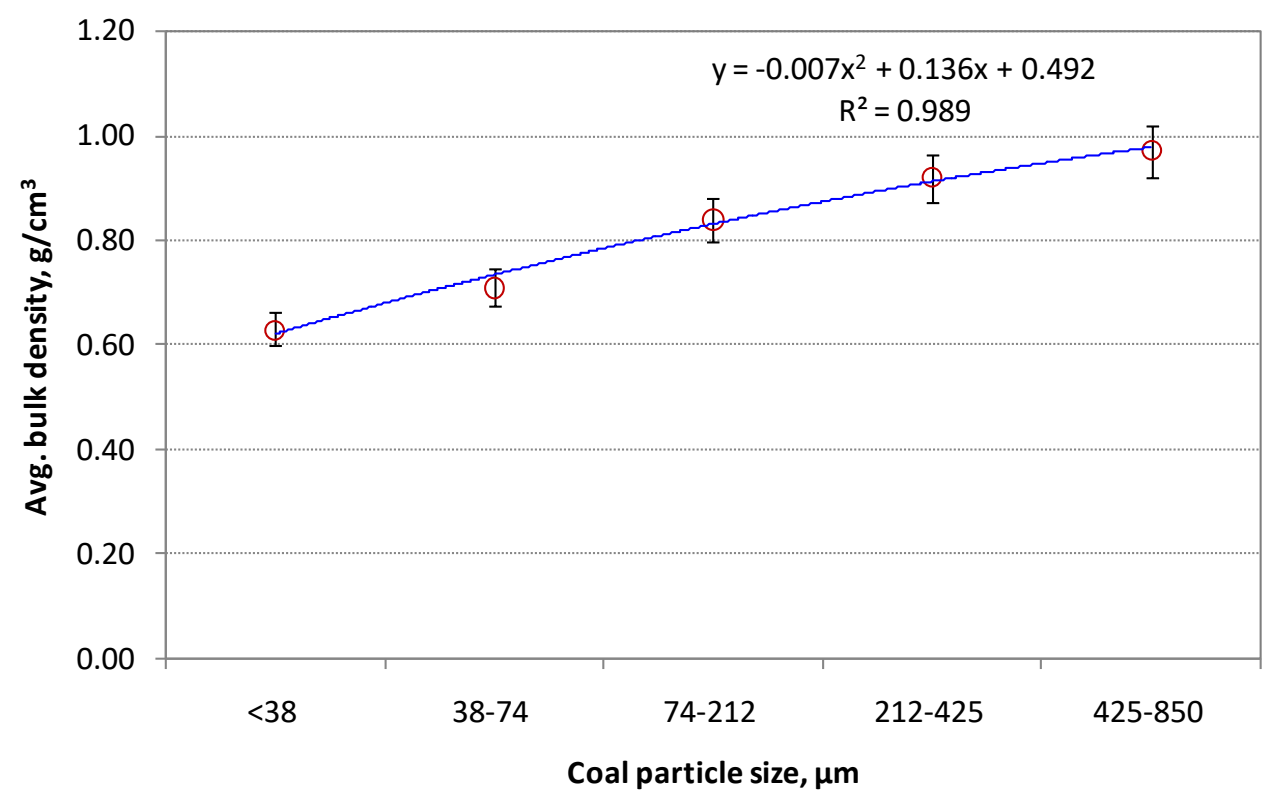

531

Fig. 4.

533

534
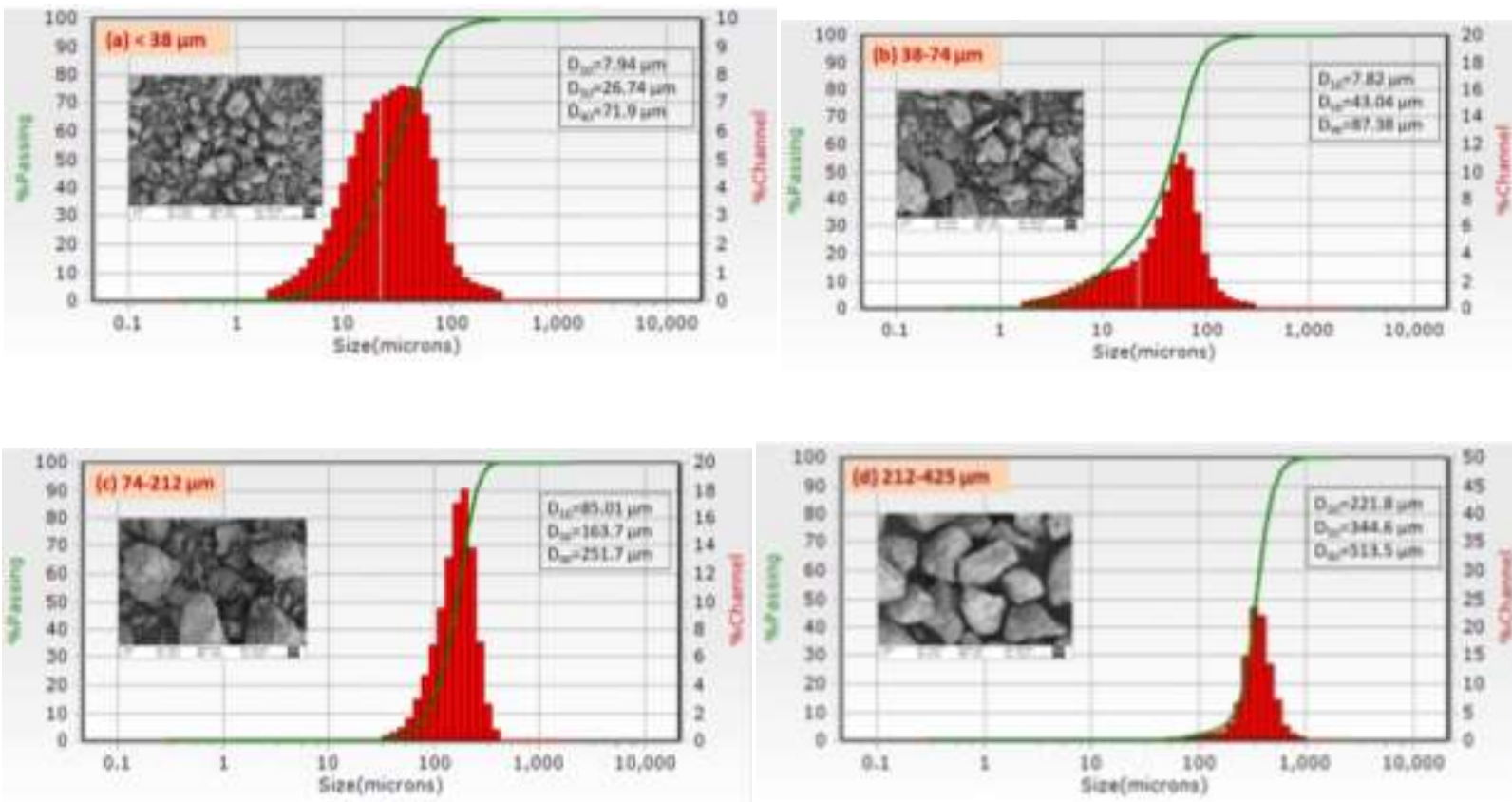

535 


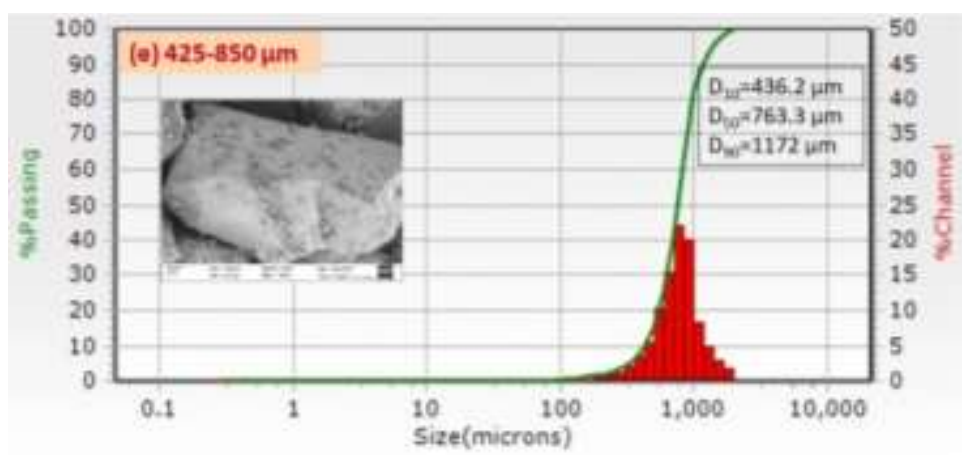

537

Fig. 5.

538

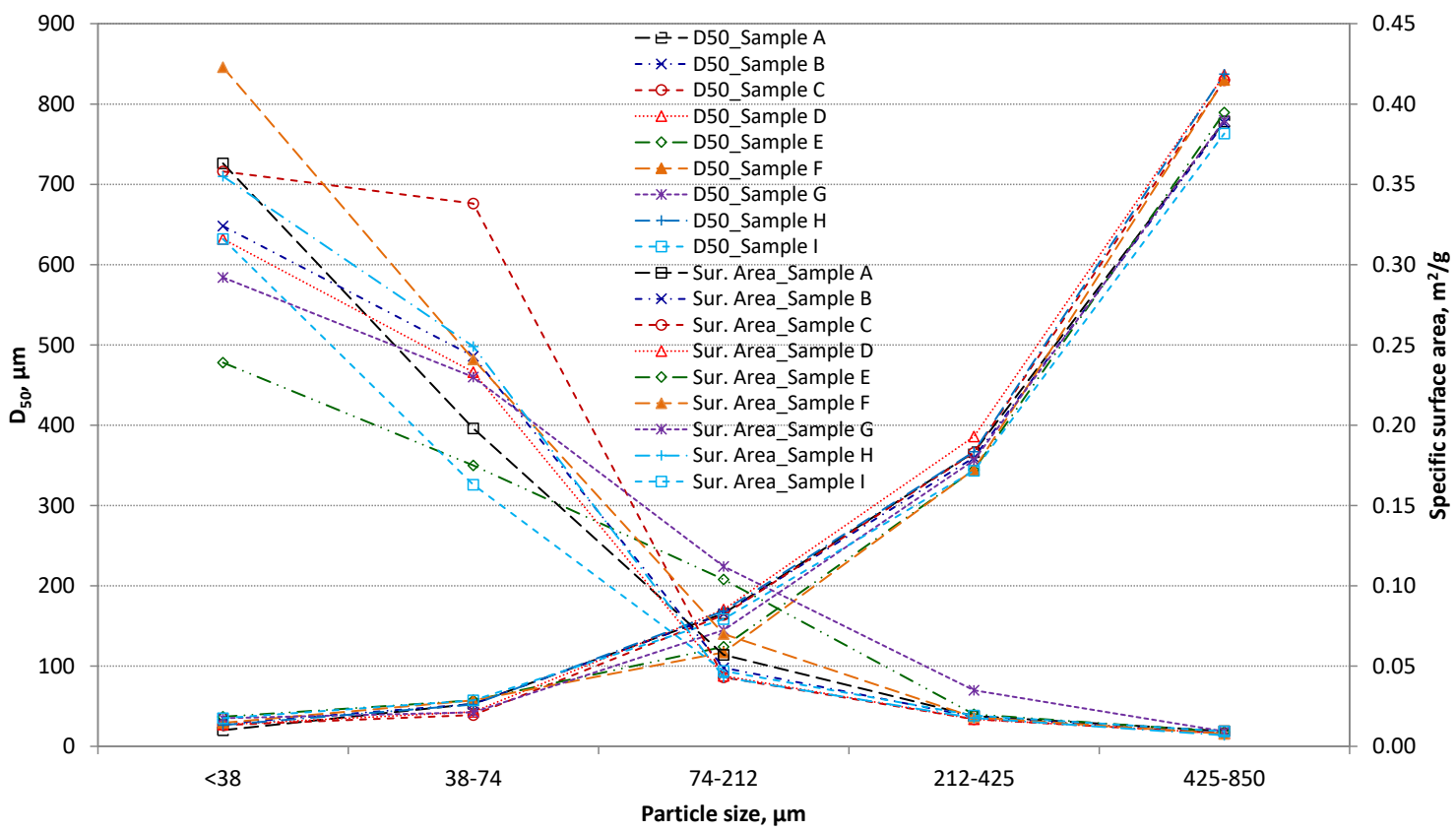

539

Fig. 6. 


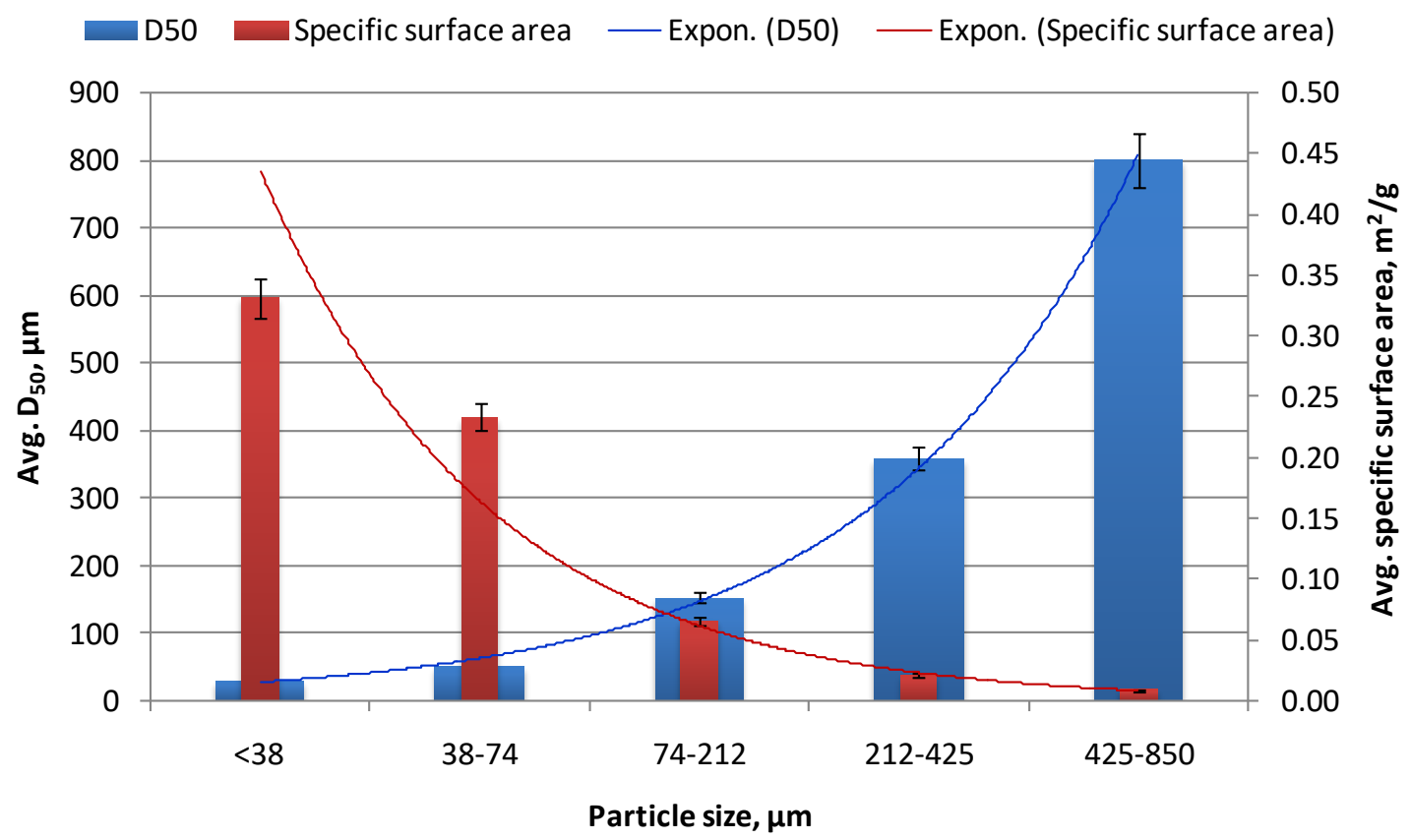

541

Fig. 7.

543

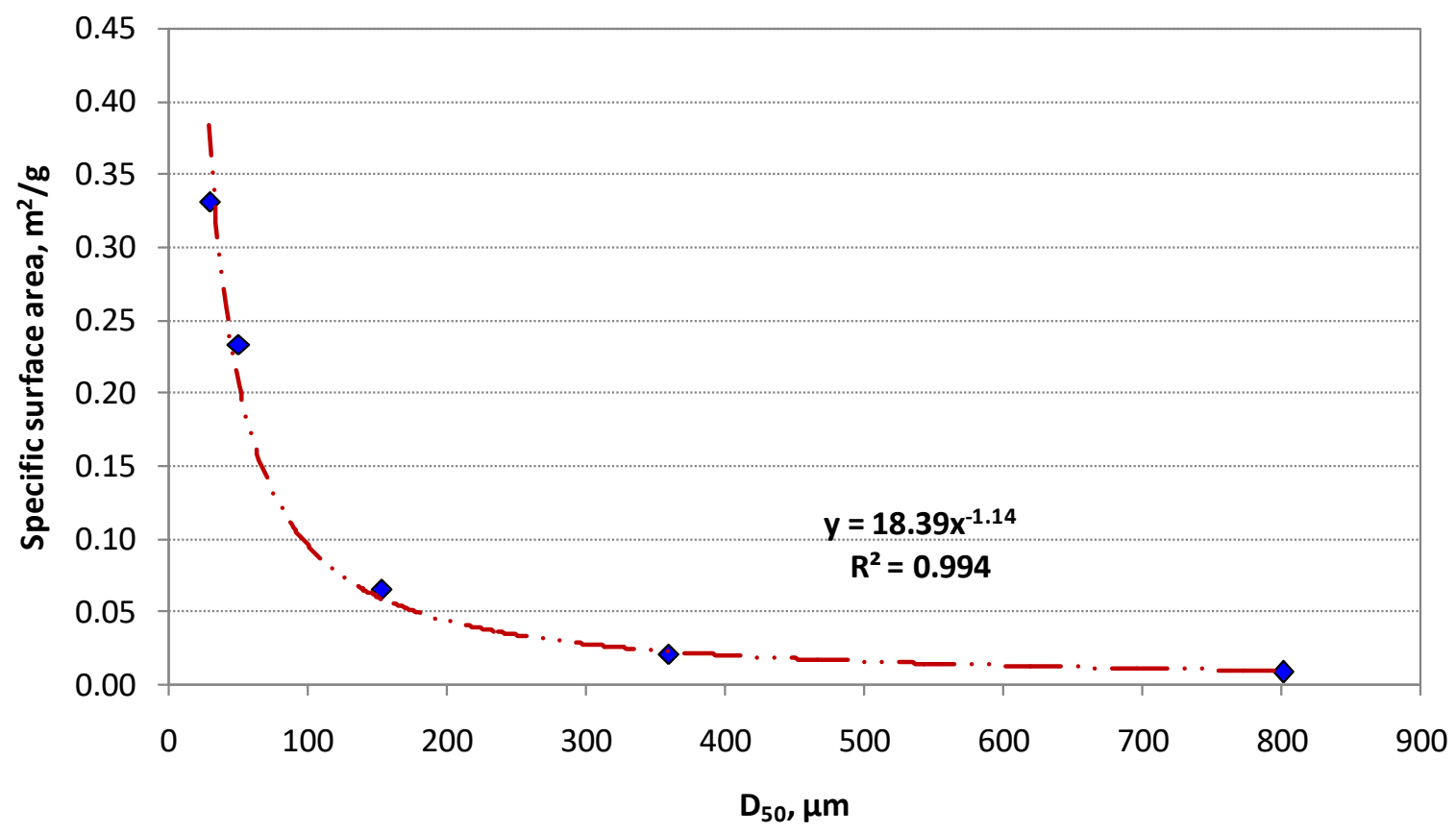

544

Fig. 8 . 


\section{6}
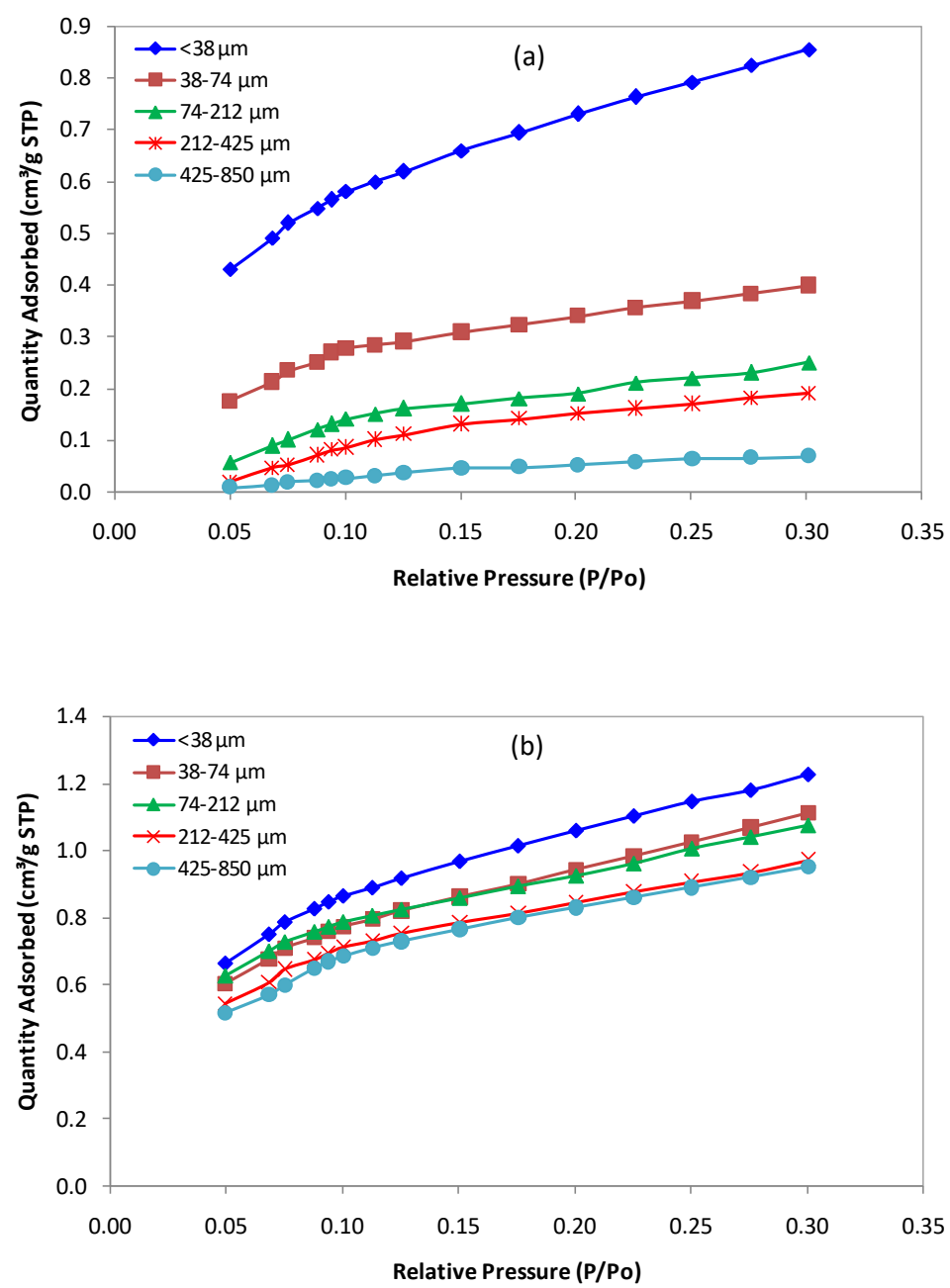

547

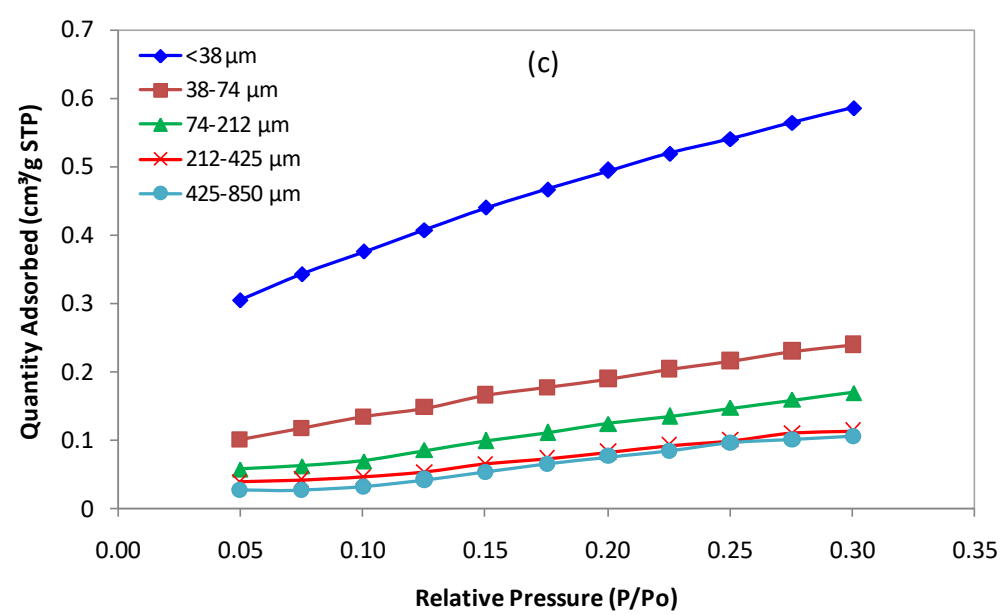

548

Fig. 9. 


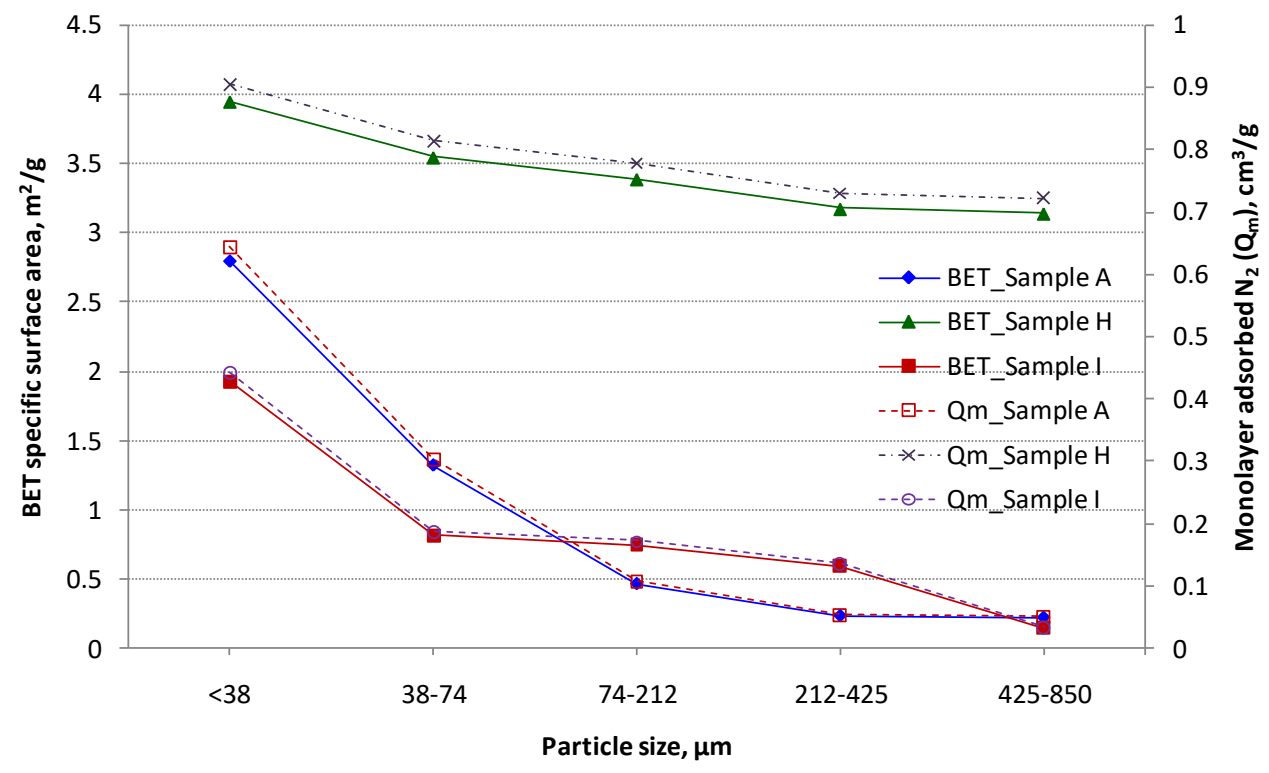

550

551

Fig. 10.

552

553

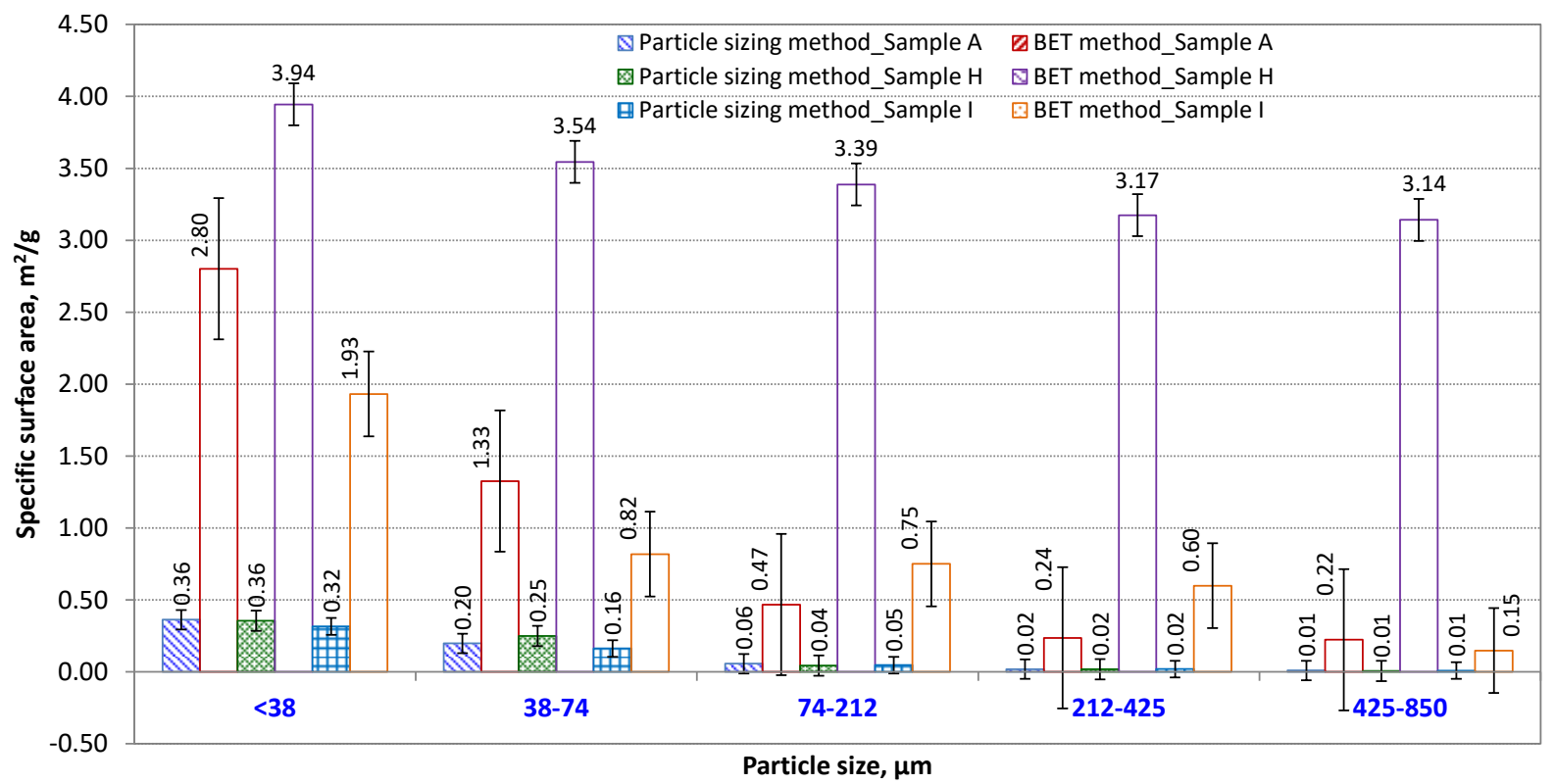

554

Fig. 11. 


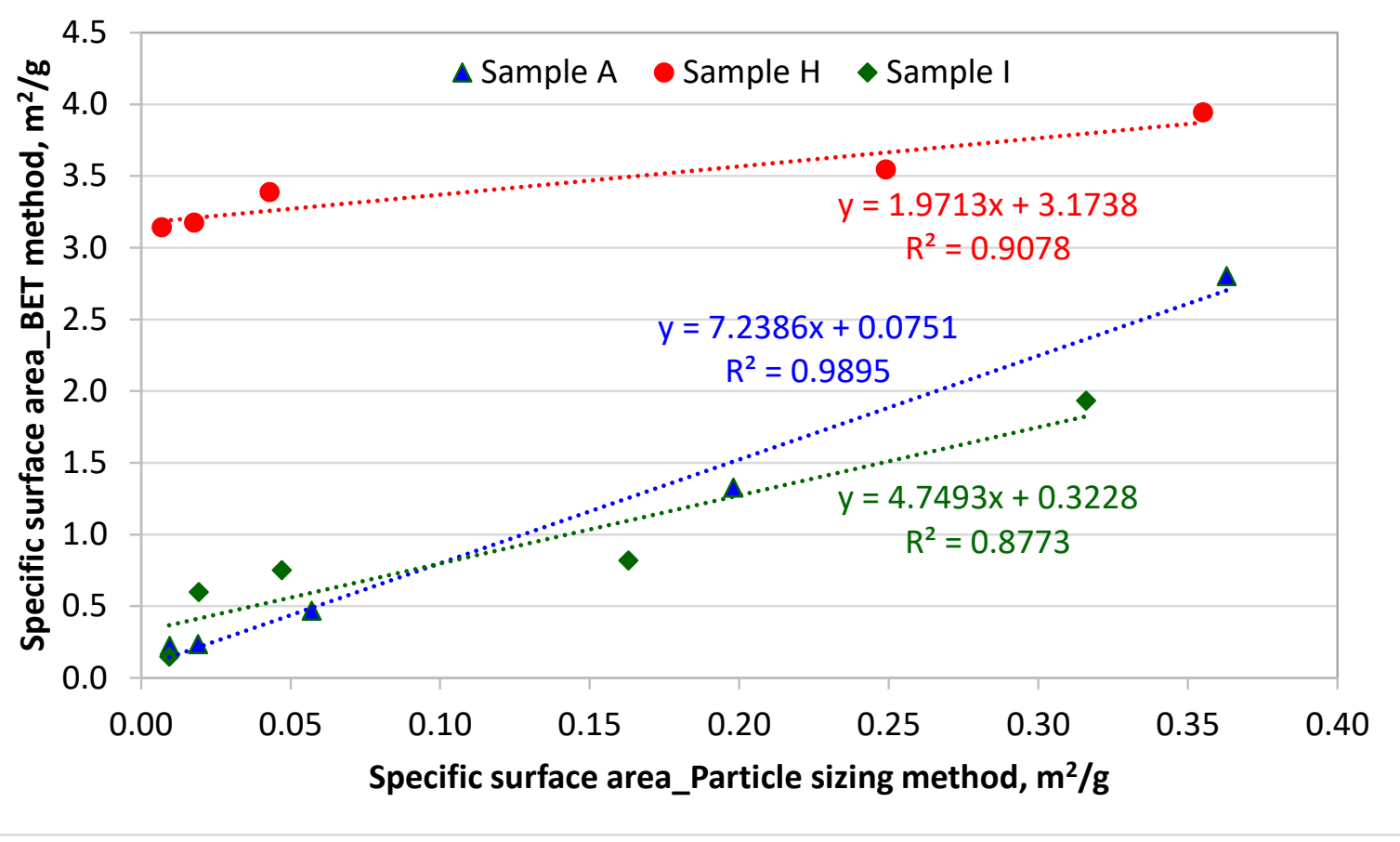

556

Fig. 12.

557

558

559

560

561

562

563

564

565 